\section{Discussion}

In recent years, the number of patients meeting the criteria for implantation of an ICD has increased dramatically. A number of creative implantation methods have been reported, but each is faced with its own set of potential complications. ${ }^{1-3}$ These complications range from postpericardiotomy syndrome ${ }^{4}$ to lead or patch trauma and failure. ${ }^{5}$

There are a number of advantages to this implantation, the first of which is that the patient avoids a median sternotomy, and the second of which is that no subcutaneous array is required, therefore eliminating the possibility of array failure.

This case is evidence that a minimally invasive approach to pediatric ICD implantation can be successful. In a patient determined to be too small for traditional transvenous implantation or with a lack of venous access, this method of ICD implantation should be considered.

\section{References}

1. Cannon BC, Friedman RA, Fenrich AL, et al. Innovative techniques for placement of implantable cardioverter-defibrillator leads in patients with limited venous access to the heart. Pacing Clin Electrophysiol. 2006;29:181-7.

2. Berul CI, Triedman JK, Forbess J, et al. Minimally invasive cardioverter defibrillator implantation for children: An animal model and pediatric case report. Pacing Clin Electrophysiol. 2004;24:1789-94.

3. Luedemann M, Hund K, Stertmann W, et al. Implantable cardioverter defibrillator in a child using a single subcutaneous array lead and an abdominal active can. Pacing Clin Electrophysiol. 2004;27:117-9.

4. Stefanelli CB, Bradley DJ, Leroy S, et al. Implantable cardioverter defibrillator therapy of life-threatening arrhythmias in young patients. J Interv Card Electrophysiol. 2002;6:235-44.

5. Kettering K, Mewis C, Dornberger V, et al. Long-term experience with subcutaneous ICD leads: a comparison among three different types of subcutaneous leads. Pacing Clin Electrophysiol. 2004;27: $1355-61$.

\title{
Argatroban anticoagulation for renal replacement therapy in patients with heparin-induced thrombocytopenia after cardiovascular surgery
}

\author{
Andreas Koster, MD, PhD, ${ }^{a}$ Thomas Hentschel, MD, ${ }^{a}$ Tom Groman, MD, ${ }^{\mathrm{b}}$ Hermann Kuppe, MD, \\ Roland Hetzer, MD, PhD, ${ }^{b}$ Sebastian Harder, MD, PhD, ${ }^{\mathrm{c}}$ and Karl-Georg Fischer, MD, PhD, ${ }^{\mathrm{d}}$ \\ Berlin, Frankfurt/Main, and Freiburg, Germany
}

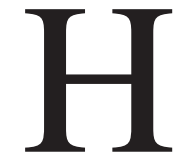
eparin-induced thrombocytopenia (HIT) is a severe thrombogenic disease requiring the use of alternative anticoagulants. Argatroban is a synthetic monovalent direct thrombin inhibitor indicated for prophylaxis and treatment of thrombosis in patients with HIT. Renal failure requiring renal replacement therapy (RRT) is a frequent complication in patients in whom HIT develops after cardiovascular surgery. The hepatic metabolism and relative short elimination half-life of 45 minutes render argatroban an interesting option for anticoagulation during RRT. However, there are scant data on dosing, pharmacokinetics, safety, and efficacy of argatroban in this indication. We report our initial experience with argatroban anti-

From the Departments of Anesthesia ${ }^{\mathrm{a}}$ and Cardiothoracic and Vascular Surgery, ${ }^{\mathrm{b}}$ Deutsches Herzzentrum Berlin, the Department of Clinical Pharmacology, Klinikum, J.W. Goethe-Universität Frankfurt/Main, ${ }^{\mathrm{c}}$ and the Department of Medicine, Division of Nephrology and General Medicine, Universitätsklinikum Freiburg, Germany. ${ }^{\mathrm{d}}$

The study was supported by the Deutsches Herzzentrum Berlin, Germany. Received for publication Nov 16, 2006; accepted for publication Jan 2, 2007.

Address for reprints: Andreas Koster, MD, PhD, Deutsches Herzzentrum Berlin, Augustenburger Platz 1, D-13353 Berlin, Germany (E-mail: koster@dhzb.de).

J Thorac Cardiovasc Surg 2007;133:1376-7

$0022-5223 / \$ 32.00$

Copyright $\odot 2007$ by The American Association for Thoracic Surgery doi:10.1016/j.jtcvs.2007.01.008 coagulation for continuous veno-venous hemofiltration (CVVH) and intermittent hemodialysis (IHD) in 10 patients diagnosed with HIT after cardiovascular surgery in whom acute renal failure developed necessitating RRT.

\section{Patients and Methods}

After approval by the local ethics committee and having obtained informed consent, we analyzed the data of 10 patients. In accordance with the study protocol, data were collected for a maximum of 30 days during RRT. Clinical follow-up of patient outcome was performed for 3 months after initiation of RRT with argatroban. All patients had thrombocytopenia after surgery or presented persistent thrombocytopenia postoperatively. In all patients the diagnosis of HIT was confirmed in an antibody assay (Particle Gel Immune Assay; DiaMed, Cressier sur Morat, Switzerland) and in the heparin-induced platelet aggregation assay. The decision to perform CVVH (Ultraflux AV 600S; polysulfone high flux hemodialyzer, Fresenius Medical Care AG, Bad Homburg, Germany) or IHD (Polyflux $140 \mathrm{H}$; polyamix high flux hemodialyzer, Gambro, Hechingen, Germany) was based on stability of hemodynamics and mobility of the patient. In general, RRT was started with CVVH and changed to IHD after hemodynamics were stable and patient mobility increased. Only in 1 patient was RRT initiated with IHD. Target activated partial thromboplastin time (aPTT) (Roche Diagnostics, Mannheim, Germany, normal value 20-22 seconds) during RRT was 50 to 80 seconds and 40 to 60 seconds in periods without CVVD or IHD. Before the start of RRT, argatroban administration was started with a continuous infusion of $1 \mu \mathrm{g} \cdot \mathrm{kg}^{-1} \cdot \mathrm{min}^{-1}$ for 1 hour. Thereafter, the aPTT was 
TABLE 1. Argatroban dose and aPTT during and between CVVH and IHD

\begin{tabular}{|c|c|c|c|c|c|c|}
\hline & $\begin{array}{l}\text { During CVVH } \\
(\mathrm{n}=9)\end{array}$ & $\begin{array}{l}\text { Between CVVH procedures } \\
\qquad(\mathrm{n}=9)\end{array}$ & $\begin{array}{c}\text { Before IHD } \\
(n=6)\end{array}$ & $\begin{array}{c}\text { During IHD } \\
(n=6)\end{array}$ & $\begin{array}{l}\text { After IHD } \\
(n=6)\end{array}$ & $\begin{array}{l}\text { Between IHD procedures } \\
(n=6)\end{array}$ \\
\hline No. of procedures & 73 & & & 29 & & \\
\hline $\begin{array}{l}\text { Argatroban } \\
\qquad\left(\mu \mathrm{g} \cdot \mathrm{kg}^{-1} \cdot \min ^{-1}\right)\end{array}$ & $0.13 \pm 0.21$ & $0.29 \pm 0.31$ & $0.07 \pm 0.11$ & $0.06 \pm 0.11$ & $0.07 \pm 0.12$ & $0.20 \pm 0.20$ \\
\hline aPTT & $64.4 \pm 12.9$ & $64.8 \pm 17.3$ & $53.4 \pm 10.6$ & $58.4 \pm 9.8$ & $54.0 \pm 16.0$ & $57.3 \pm 16.2$ \\
\hline
\end{tabular}

aPTT, Activated partial thromboplastin time; CVVH, continuous veno-venous hemodialysis; $I H D$, intermittent hemodialysis.

measured and RRT started. During the procedures, argatroban infusion rates were adjusted to target values in increments of 0.25 $\mu \mathrm{g} \cdot \mathrm{kg}^{-1} \cdot \min ^{-1}$ depending on the results of coagulation tests.

\section{Results}

There were 7 male and 3 female patients. The mean age was $58.8 \pm$ 11.0 years. Surgery performed was implantation of a ventricular assist device in 2 patients, heart transplantations in 3, lung transplantation in 1, pulmonary artery thrombectomy in 1, replacement of a thoracoabdominal aortic aneurysm in 1, and coronary artery bypass grafting in 2 . No bleeding events attributed to problems of anticoagulation were observed. Five patients died during the observation period. Data for argatroban dosing and aPTT values are presented in Table 1. The total duration of the $73 \mathrm{CVVH}$ procedures was 2252 hours with a mean of $30.8 \pm 27.1$ hours. The total duration of the 29 IHD procedures was 160 hours with a mean of $3.9 \pm 1.0$ hours. No filter system had to be exchanged during IHD as a result of premature filter thrombosis.

\section{Discussion}

This is the first investigation providing a dosing regimen for the use of argatroban during RRT in patients with HIT after cardiovascular surgery. Our data provide convincing evidence that in these patients the current protocol provides safe and effective anticoagulation for $\mathrm{CVVH}$ and IHD. The data obtained suggest the following:

1. In view of the good patency of filters of approximately 30 hours and the low rate of bleeding complications, prolongation of the aPTT to the 3- to 4-fold appears to be safe and effective for argatroban anticoagulation for both CVVH and IHD in this patient population.

2. In a previous investigation, $\mathrm{we}^{1}$ demonstrated that argatroban dosing in patients after cardiovascular surgery is considerably lower than in medical patients and that the anticoagulant effect of the drug is immediately achieved by continuous infusion so that no bolus administration is necessary. In line with these observations, in our patients the mean argatroban infusion rate during RRT of 0.06 to 0.12 $\mu \mathrm{g} \cdot \mathrm{kg}^{-1} \cdot \min ^{-1}$ was considerably lower than the median infusion rate of $1.7 \mu \mathrm{g} \cdot \mathrm{kg}^{-1} \cdot \mathrm{min}^{-1}$ in medical patients. Moreover, a starting infusion rate of $1 \mu \mathrm{g} \cdot \mathrm{kg}^{-1} \cdot \mathrm{min}^{-1}$ for
1 hour provided reliable anticoagulation for the initiation of RRT, so that no bolus administration was necessary. ${ }^{2}$

3. In contrast to observations with the other direct thrombin inhibitors, bivalirudin and lepirudin, and in line with previous observations, the fact that argatroban dosing during and after CVVH and IHD was almost comparable with dosing during intervals without RRT suggests only minor elimination of the drug via the filter system. ${ }^{3-5}$ However, elimination of argatroban appears to be slightly more pronounced during CVVH.

On the basis of these observations, we conclude that dosing of argatroban according to the protocol outlined here provides reliable, safe, and effective anticoagulation during CVVH and IHD in patients with HIT after cardiovascular surgery. Inasmuch as the argatroban elimination half-life of 45 minutes is relatively short, elimination is independent of renal function and, as we observed, extracorporeal elimination during both CVVH and IHD is clinically insignificant, so that no dose adjustment is necessary during RRT, argatroban anticoagulation appears to be an excellent option in this indication. However, further detailed studies are needed to confirm this assumption.

\section{References}

1. Koster A, Buz S, Hetzer R, Kuppe H, Breddin K, Harder S. Anticoagulation with argatroban in patients with heparin-induced thrombocytopenia antibodies after cardiac surgery with cardiopulmonary bypass: first results from the ARG-E03 trial. J Thorac Cardiovasc Surg. 2006; 132:699-700.

2. Reddy BV, Grossman EJ, Trevino SA, Hursting MJ, Murray PT. Argatroban anticoagulation in patients with heparin-induced thrombocytopenia requiring renal replacement therapy. Ann Pharmacother. 2005;39:1601-5.

3. Koster A, Merkle F, Hansen R, Loebe M, Kuppe H, Hetzer R, et al. Elimination of recombinant hirudin by modified ultrafiltration during simulated cardiopulmonary bypass: assessment of different filter systems. Anesth Analg. 2000;91:265-9.

4. Koster A, Chew D, Gruendel M, Hausmann H, Grauhahn O, Kuppe H, et al. An assessment of different filter systems for extracorporeal elimination of bivalirudin: an in vitro study. Anesth Analg. 2003;96:1316-9.

5. Tang IY, Cox DS, Patel K, Reddy BV, Nahlik L, Trevino S, et al. Argatroban and renal replacement therapy in patients with heparininduced thrombocytopenia. Ann Pharmacother. 2005;39:231-6. 